\title{
Effects of Economic Recession on Road Safety Indexes
}

\author{
Marta Rojo \\ Assistant Professor, University of Burgos, Spain \\ Hernán Gonzalo-Orden \\ Professor, University of Burgos, Spain \\ Alaitz Linares \\ Researcher, University of Burgos, Spain \\ Luigi dell'Olio \\ Professor, University of Cantabria, Spain
}

\begin{abstract}
During the last years, the investment in both construction and conservation of transport infrastructures has been considerably reduced in several countries, as Spain. After a number of years in which economic circumstances have forced Governments to reduce budgets earmarked for the maintenance and creation of new ways, it is interesting to analyze whether this has taken a toll on accident rates.
\end{abstract}

The paper evaluates if there are significant changes in the road safety through these years in Spain, comparing the annual statistics concerning investment in infrastructure and accidents. Thus, the classical risk, mortality and severity indexes have been analyzed to understand their real trends. Finally, through linear regression techniques, it is shown how these trends are related to the budgets invested each year, in order to draw interesting conclusions about the effect of their reduction.

\section{INTRODUCTION}

The economic difficulties of the Governments of different countries have resulted that, in recent years, contributions for construction and maintenance of roads have been considerably reduced. But on the other hand, during the years of economic crisis, the number of movements on the roads and the length of them have dropped. Therefore, this article analyzes the impact of this decrease in budgets on the usual road safety indexes: risk, mortality and severity.

After this first chapter of introduction to the problem, Chapter 2 shows the evolution of the parameters of study over the years. Comparisons between risk levels and budgets are collected in Chapter 3, where the relationship between them, using linear regression techniques, is discussed. Finally, Chapter 4 includes the main findings of the study. 


\section{DATA ANALYSIS}

In this section, the evolution of the budgets reserved for roads and the traffic accidents registered in Spain will be presented, as well as other economic aspects, such as the fleet of vehicles or the variations in reported traffic volumes.

\subsection{Economic Analysis}

In the first place, data from the budgets of the Spanish Ministry of Development have been collected, both in their total values as only those for roads -construction or maintenance-. This information has been obtained from Ministerio de Fomento (2008-2016). Figure 1 shows their evolution between 2008 and 2016 (provided this last). There, we can see that there was generalized decrease of budgets, while from 2015 the trend starts to be ascending.

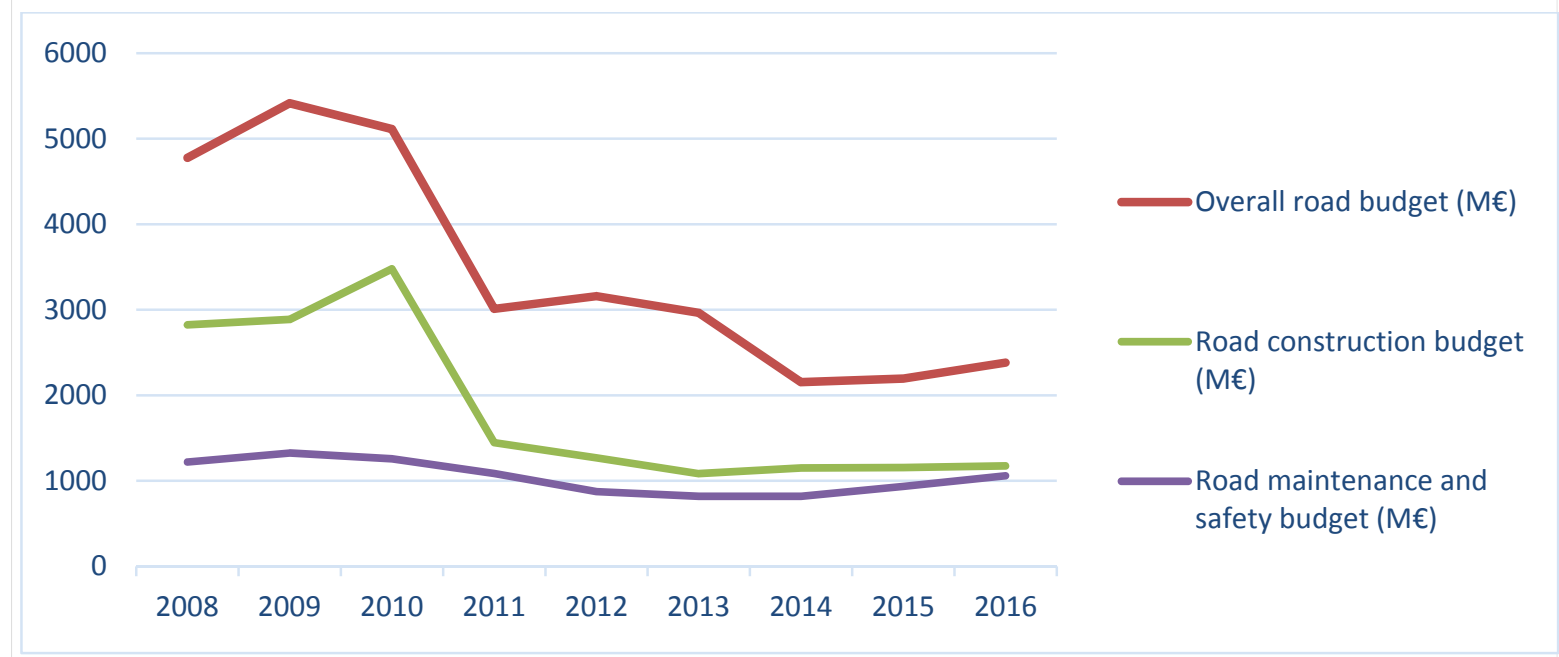

Fig. 1 - Evolution of investment in roads

On the other hand, it is also interesting to analyze how the vehicle fleet and the total traffic recorded on the tracks have evolved during the years of the crisis, in order to establish comparisons in this regard. Such data have been obtained from Ministerio de Fomento (2015a), as well as documents that collect the main figures of the accident road (Dirección General de Tráfico, 2009-2015), and are included in Figure 2. There, we can see that the vehicle fleet has had two 'valley' years (2009 and 2013), and that in 2014, there was a small increase compared to the previous year. However, the volume of traffic (measured in millions of vehicle-kilometer) has been decreasing during the crisis, although in the year 2014 the trend changes, increasing with respect to 2013. 


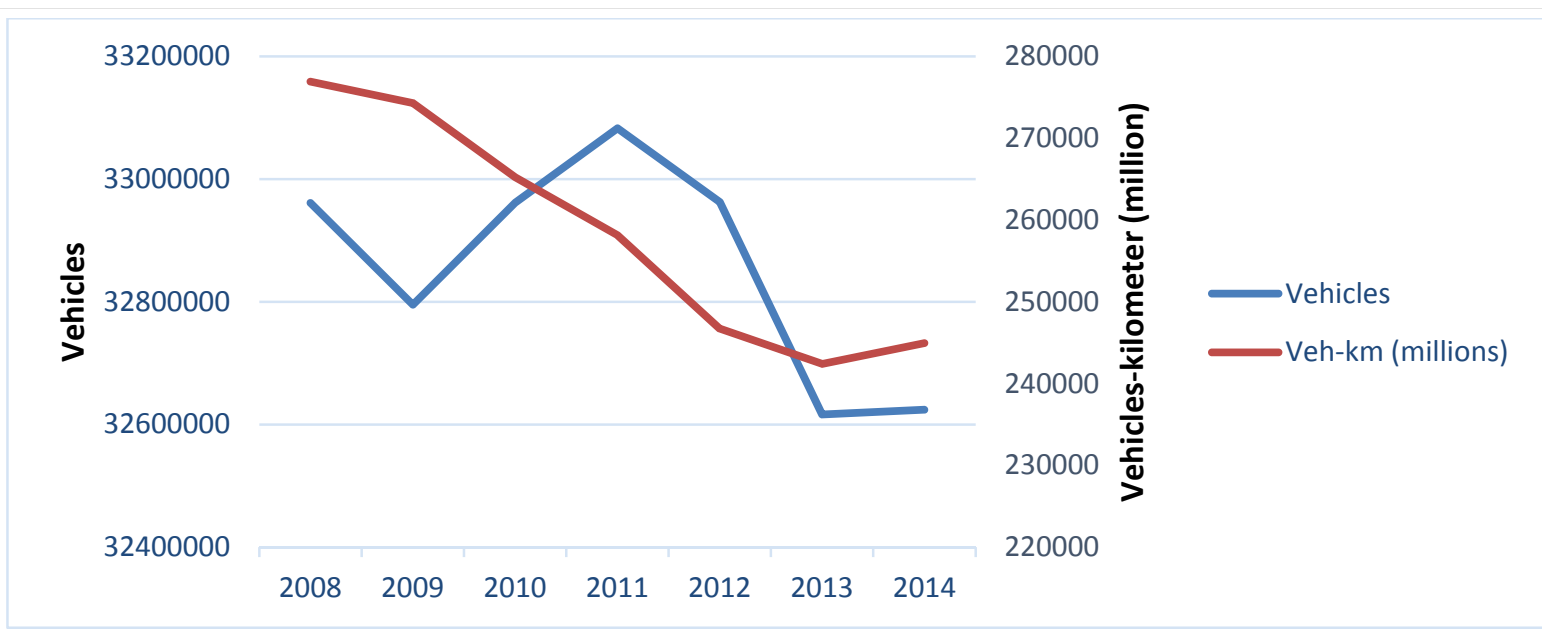

Fig. 2 - Evolution of vehicle fleet and registered traffic

Regarding the distribution of the fleet of vehicles, it is necessary to emphasize that in 2014, $68 \%$ of them were light vehicles, $15 \%$ trucks and vans, $15 \%$ motorcycles and mopeds, and the remaining $2 \%$ composed by buses, tractors and other vehicles. Finally, in terms of their age distribution, it is noted that 50 percentile is 10.5 years. Distinguishing by type of vehicle, average age is 10.5 years for light vehicles and 11.5 years for trucks and vans (Dirección General de Tráfico, 2015).

\subsection{Road Safety Analysis}

Once analyzed the economic evolution during the crisis, data on the evolution of accidents will be presented about Spanish roads. So, first of all data on the number of accidents and the number of victims of fatal (within 30 days) will be presented, taken from Dirección General de Tráfico (2009-2015, 2016) and RACC (2016). The obtained results are shown in Figure 3.

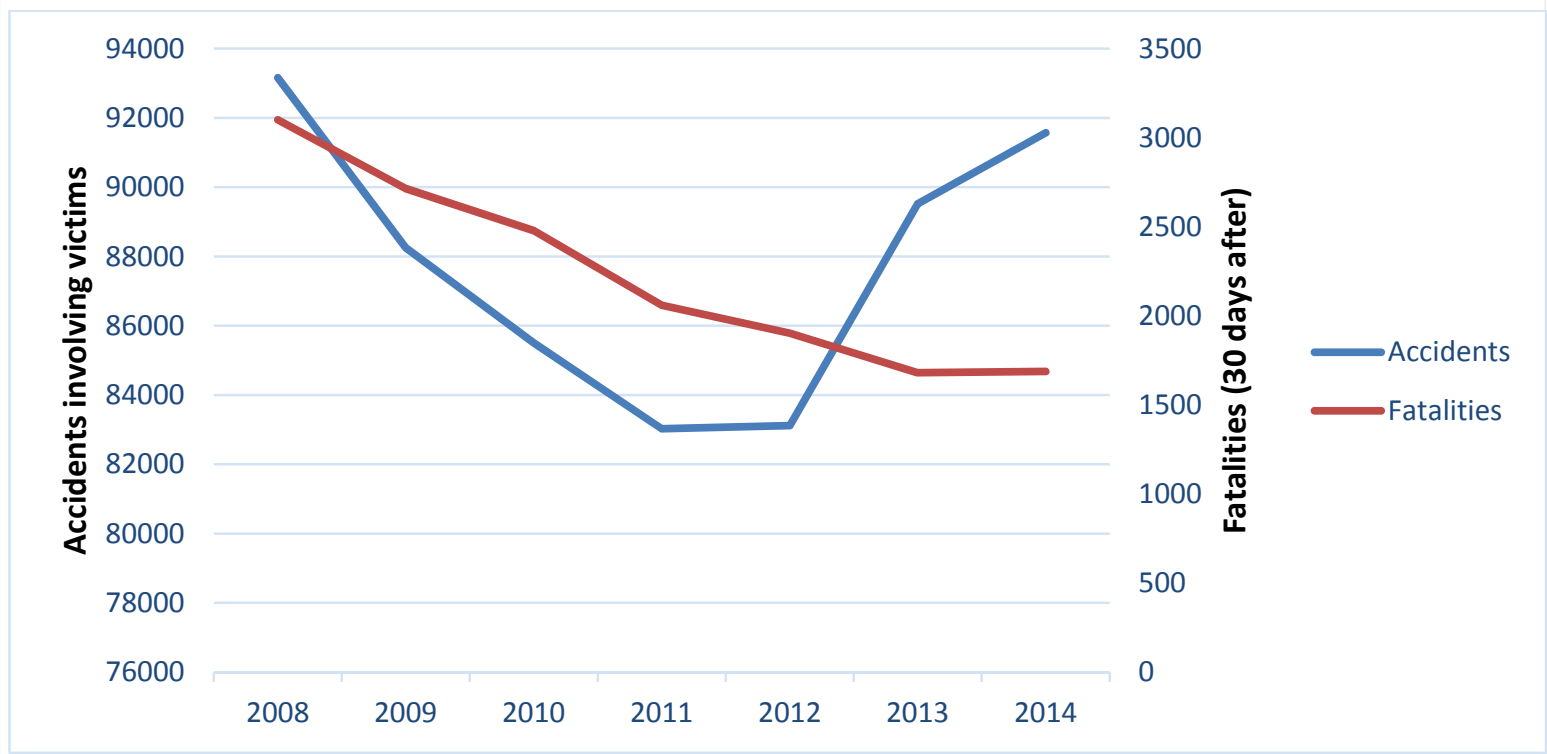

Fig. 3 - Evolution of accidents 
As we can see, even though the number of fatalities is being reduced with the passing of the years, from 2011 is noted a clear increase in the number of accidents with victims. The decline in the number of deaths may be associated with increasingly better vehicles passive safety systems, which reduce personal injuries despite having an accident. However, the fact that accidents skyrocket from certain date seems to indicate some relationship with the reductions in the budgets for roads and, therefore, for conservation.

To verify this hypothesis, the usual road safety indices have been calculated: risk, mortality and severity indexes. The risk index indicates the probability of an accident of traffic for each driven kilometer. Mortality index is similar, but with the likelihood of death in a traffic accident. Finally, the severity index indicates the probability of dying once an accident has been occurred. Their values have been determined according to the formulation that follows:

$$
\begin{gathered}
\text { Risk Index }=R I=\frac{\text { Number of accidentes involving victims }}{10^{8} \text { vehicles }- \text { kilometer }} \\
\text { Mortality Index }=M I=\frac{\text { Number of fatalities }}{10^{8} \text { vehicles }- \text { kilometer }} \\
\text { Severity Index }=S I=\frac{\text { Number of fatalities }}{100 \text { accidentes involving victims }}
\end{gathered}
$$

Thus, from the data previously exposed, such indices have been calculated for the different years of the period under analysis. The obtained results are presented in Figure 4.

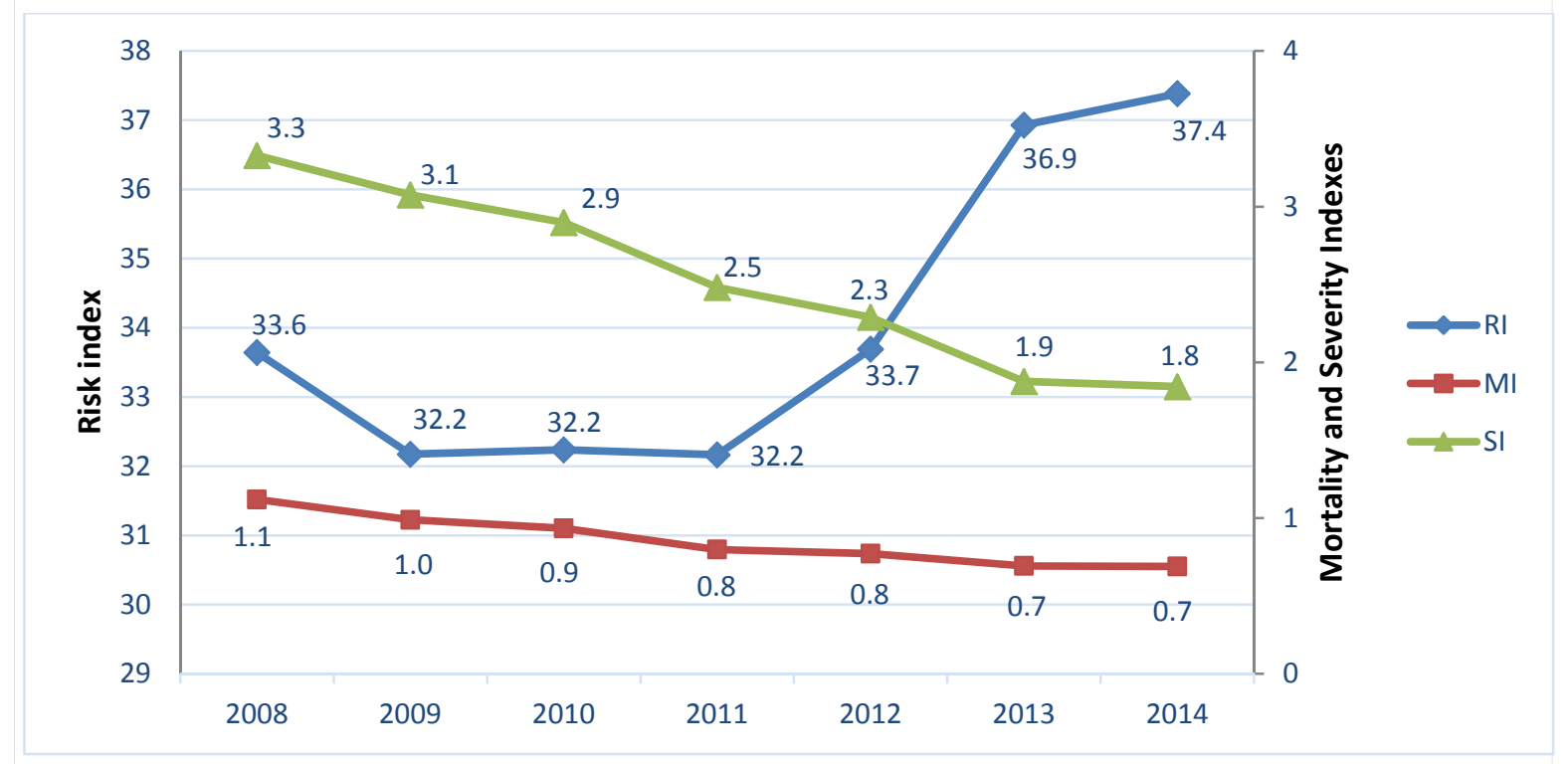

Fig. 4 - Evolution of the road safety indexes 
We can appreciate the severity and mortality indexes are, fortunately, descending with the passage of the years. But this decline is very conditioned to the automobile passive safety systems, increasingly more developed and more efficient.

Analyzing the risk index, a clear increase from years 2009-2011 is observed, as a result of the increase in the number of accidents, together with the decrease in the total length of journeys made in recent years. Its possible relationship with investments aimed at the conservation and maintenance of roads will be discussed in subsequent chapters.

\section{RELATIONSHIP BETWEEN ANNUAL BUDGETS AND SAFETY INDEXES}

From the collection of data from annual budgets outlined in previous chapters, the possible relationship between them and the rate of endangerment will be analyzed. This index was selected, among the different calculated, because it is the least affected by the automobile passive safety systems, increasingly better and more widespread among the vehicle fleet. Table 1 summarizes data used for this analysis.

\begin{tabular}{|c|c|c|c|c|c|}
\hline Year & $\begin{array}{c}\text { Overall road } \\
\text { budget (M€) }\end{array}$ & $\begin{array}{c}\text { Road } \\
\text { construction } \\
\text { budget (M€) }\end{array}$ & $\begin{array}{c}\text { Road maintenance } \\
\text { and safety budget } \\
(\mathrm{M} €)\end{array}$ & $\begin{array}{c}\text { No. veh-km } \\
\left(10^{6}\right)\end{array}$ & RI \\
\hline 2008 & 4778 & 2822 & 1219 & 276,924 & 33.64 \\
\hline 2009 & 5414 & 2886 & 1324 & 274,308 & 32.17 \\
\hline 2010 & 5114 & 3478 & 1257 & 265,244 & 32.24 \\
\hline 2011 & 3011 & 1445 & 1085 & 258,146 & 32.16 \\
\hline 2012 & 3160 & 1268 & 873 & 246,714 & 33.69 \\
\hline 2013 & 2963 & 1084 & 818 & 242,415 & 36.93 \\
\hline 2014 & 2153 & 1148 & 818 & 244,958 & 37.38 \\
\hline
\end{tabular}

Table 1 - Overview of economic data and risk index

Next, correlation between the different exposed budgets and the risk index has been estimated, through linear regression techniques. The results are those shown in Figures 5 to 7. There we can appreciate a real relationship between the decrease in annual budgets with the risk index, i.e., with the probability of an accident through pathways. But that relationship is especially significant when we consider not the global budgets, but specifically those for operations of conservation; in that case, we can observe that the coefficient of determination $\mathrm{R}^{2}$ reaches a value of $67 \%$. 


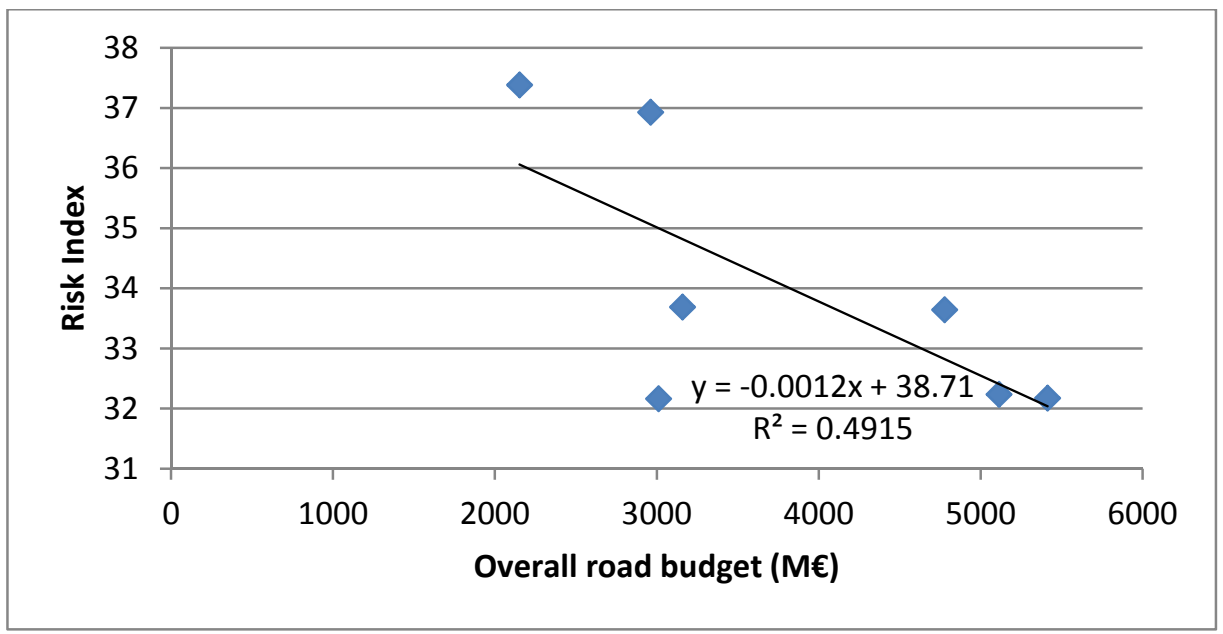

Fig. 5 - Relationship between risk index and overall road budget

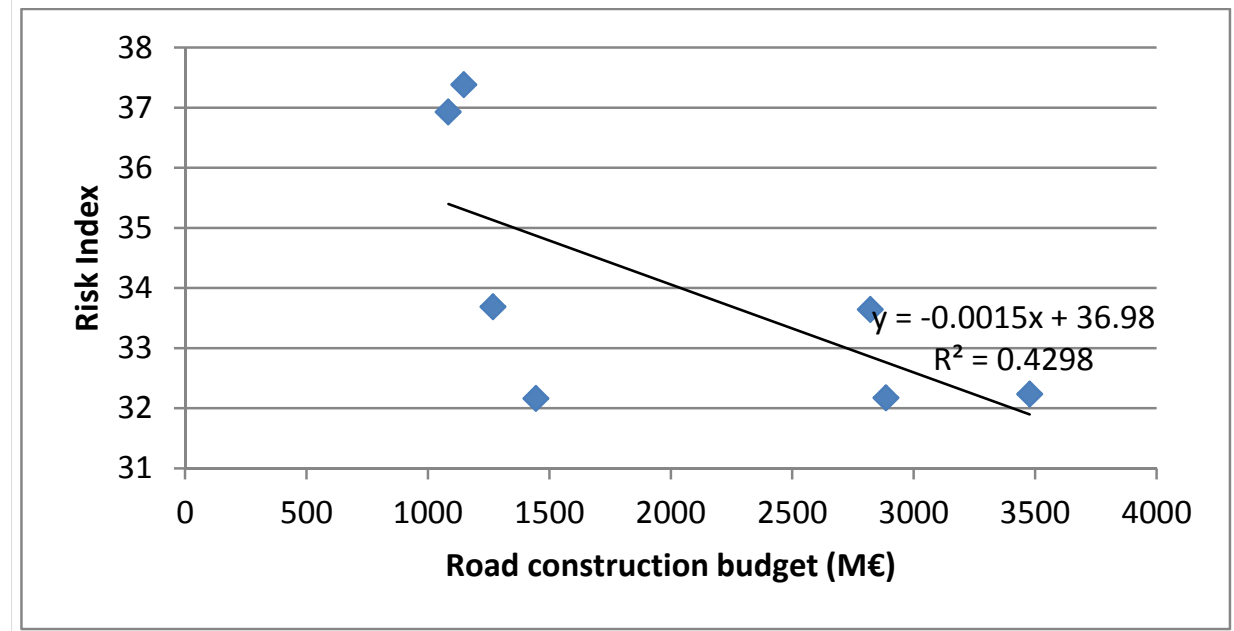

Fig. 6 - Relationship between risk index and road construction budget

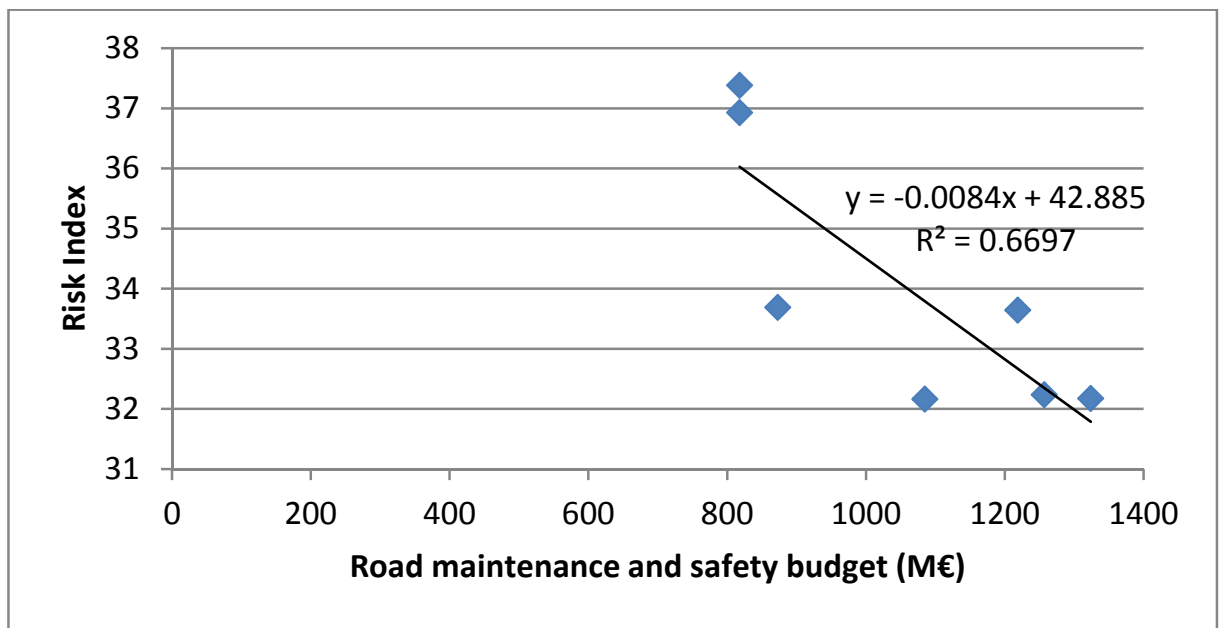

Fig. 7 - Relationship between risk index and road maintenance and safety budget

Even more enlightening is the analysis of the relationship of the risk index not with budgets of the corresponding year, but with the average of the previous years. Figure 8 shows the results of this relationship. There we can see that the coefficients of 
determination $\mathrm{R}^{2}$ reach highly significant values: $89 \%$ with the average of the last 2 years and $96 \%$ with the last 3 years.
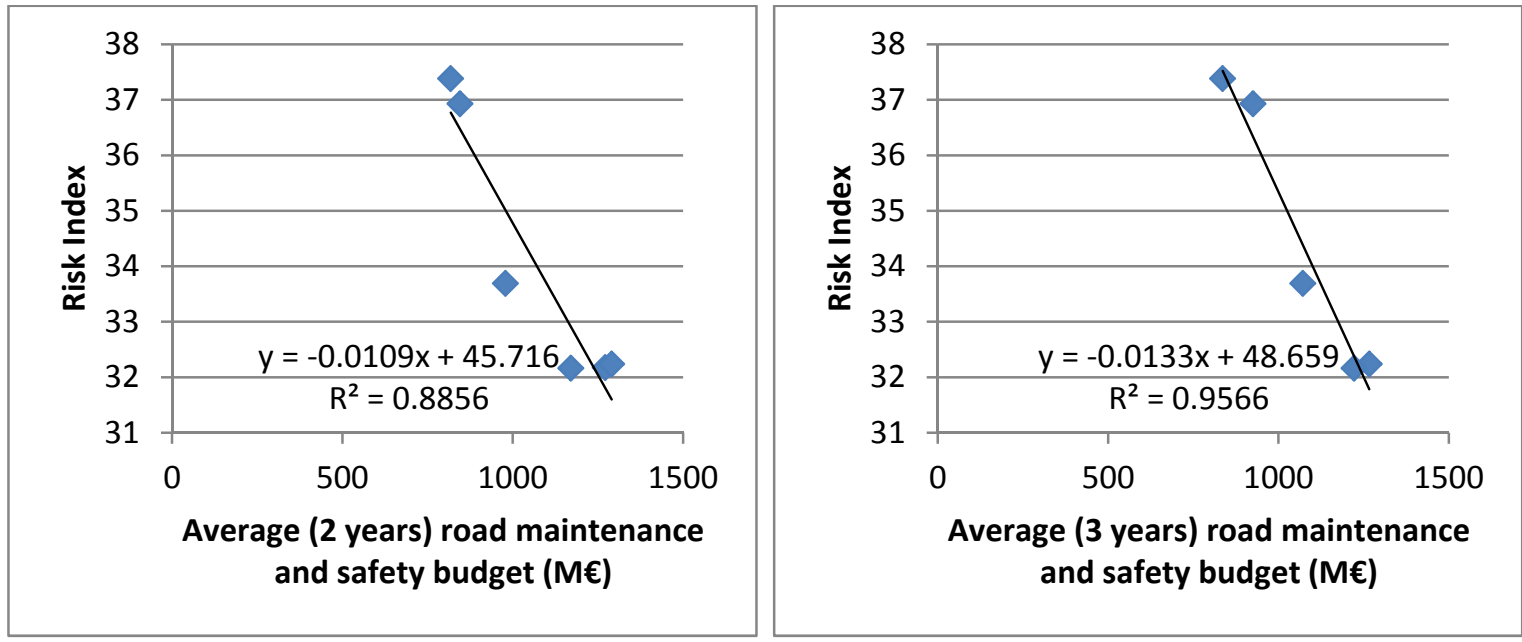

Fig. 8 - Relationship between risk index and average values (last 2-3 years) of the road maintenance and safety budget

Therefore, we can close this chapter by indicating that there is a real and direct relationship between the budgets designed for roads with their endangerment. This relationship is much more clear and intense when we specifically analyze budgets directed to conservation operations, reaching determination coefficients among these factors higher than $66 \%$. And even if we do not consider the annual value of budgets, but the average of the previous years (much more realistic, since degradation of ways impact more on road safety of subsequent years that of the corresponding year), the coefficient of determination reaches levels above $90 \%$.

\section{CONCLUSIONS}

This article has analyzed how the economic crisis suffered in certain countries, such as Spain, has affected both the investment in road infrastructure and traffic flowing through them and road safety. According to the obtained results, we can note four main conclusions:

1. The total budget available for roads has considerably decreased each year during the economic crisis. The part aimed at the construction of new roads has suffered the greatest impact, having diminished by 58\% between 2008 and 2016. The investment destined to conservation has also suffered the crisis, even though the relative magnitude of this decrease was not so high: $33 \%$ of reduction between 2008 and 2014.

2. Traffic that circulated by the Spanish roads in 2014 is widely below the values of 2008. In fact, there has been a monotonically decreasing trend from 2008 until 
2013, from which there is a turning point, returning to the growing tendency of previous stages.

3. In terms of accident statistics, even though the number of fatalities continues a downward trend, the number of accidents with victims hasn't the same one, since it has experienced high growth from the year 2011. In fact, it has increased more than 10\% between that date and 2014.

4. Finally, analyzing road safety indices, we considered that the most representative one is the risk index, since others are more strongly influenced by the passive safety of vehicles, more and more advanced systems and that, therefore, prevent deadly casualties despite the existence of serious accidents. Therefore, it was detected that a relationship between this risk index with the budgets for both new investment and conservation exists, and it is more intense if we consider only the budgets for conservation. In fact, if we relate the mean of these budgets for conservation of the past years with the risk index, determination coefficients higher than $90 \%$ are obtained.

Therefore, it can be concluded that the relationship between the budgets for investment in road infrastructure and their safety exists, and it can be measurable. This relationship is stronger if we specifically consider the budgets for roads maintenance and safety operations.

This clues us to conclude with the need to maintain the investment in road infrastructure (other large investments in transport could have reduced their budgets instead) also in times of crisis, since this affects the accident rates of our ways, which has both social and economic consequences.

\section{REFERENCES}

DIRECCIÓN GENERAL DE TRÁFICO. Las Principales Cifras de la Siniestralidad Vial. España 2008-2014. Ministerio del Interior, Spain Government, 2009-2015. DIRECCIÓN GENERAL DE TRÁFICO. Balance de Seguridad Vial 2015. Ministerio del Interior, Spain Government, 2016.

MINISTERIO DE FOMENTO. Anuario Estadístico 2014. Spain Government, 2015a. MINISTERIO DE FOMENTO. Presupuestos Generales del Estado. Spain Government, 2008-2016.

RACC. Análisis del Estancamiento de la Siniestralidad en las Carreteras Españolas durante 2015. RACC Automóvil Club, 2016. 